\title{
Controlling the formation of metallosupramolecular assemblies by metal ionic radii $\dagger$
}

\author{
Lindsay Bain, ${ }^{a}$ Sam Bullock, ${ }^{a}$ Lindsay Harding, ${ }^{a}$ T. Riis-Johannessen, ${ }^{b}$ Gary Midgley, ${ }^{a}$ \\ Craig R. Rice ${ }^{* a}$ and Martina Whitehead ${ }^{a}$
}

Received 7th October 2009, Accepted 24th March 2010

First published as an Advance Article on the web 14th April 2010

DOI: $10.1039 / b 920840 b$

The formation of either dinuclear double-stranded or pentanuclear circular helicates from a ligand containing two tridentate domains separated by a phenylene unit can be controlled by inter-ligand steric interactions which themselves are governed by the size of the metal ion.

Controlling the structure of multi-component assemblies is one of the leading challenges for the supramolecular chemist. One of the simplest assemblies is the dinuclear doublestranded helicate, and the rules that govern the formation of this species are largely established. ${ }^{1-7}$ The formation of the helicates' higher nuclearity cousin, the cyclic helicate, is conversely less well understood. One of the major problems in the formation of these higher nuclearity assemblies is that the design principles that apply to helicate formation, i.e. using a ligand that contains two binding domains that coordinate different metal ions, equally apply to the formation of cyclic helicates. For the larger cyclic species to preside in solution, the formation of the entropically favoured dimer has to be prevented and this can be achieved by intermolecular interactions (e.g. templation by anions) ${ }^{8}$ or by intramolecular interactions which stabilise the formation of the cyclic species relative to its double-stranded alternative. As an example of the first of these approaches, in the work carried out by Ward et al., a ligand with two bidentate domains separated by a 1,8-naphthalenediyl spacer was reported to form a simple mononuclear species with $\mathrm{Cu}\left(\mathrm{CF}_{3} \mathrm{SO}_{3}\right)$, but in the presence of tetrafluoroborate, a tetranuclear cyclic helicate $\left[\mathrm{Cu}_{4} \mathrm{~L}_{4}\right]^{4+}$ was observed. ${ }^{9}$ Hannon et al., on the other hand, demonstrated that a metal ion's preference for different coordination geometries could affect the self-assembly outcome. In this case a bis-bidentate ligand containing a 1,3-bis(aminomethyl)phenyl spacer formed linear dimers with tetrahedral metal ions and trinuclear circular helicates with octahedral metal ions. ${ }^{10}$ Other reports have cited inter-strand $\mathrm{CH} \cdots \pi$ interactions as the principal driving force for the preferential formation of high complexity cyclic assemblies over their dimeric

\footnotetext{
${ }^{a}$ Department of Chemical and Biological Sciences,

University of Huddersfield, Huddersfield HD1 3DH, UK.

E-mail: c.r.rice@hud.ac.uk; Fax: +44(0)148-447-2182

${ }^{b}$ EPFL SB ISIC LCS, BCH 3307 (Bâtiment de chimie UNIL),

CH-1015, Lausanne, Switzerland

$\dagger$ Electronic supplementary information (ESI) available: Ligand synthesis and characterisation; ${ }^{1} \mathrm{H} /{ }^{1} \mathrm{H}$ COSY and NOESY spectra for $\left[\mathrm{Cd}_{2}\left(\mathrm{~L}^{1}\right)_{2}\right]^{4+}$ and $\left[\mathrm{Zn}_{5}\left(\mathrm{~L}^{1}\right)_{5}\right]^{10+}$; details of crystallographic refinements. CCDC 748335 and 748336 . For ESI and crystallographic data in CIF or other electronic format see DOI: 10.1039/b920840b
}

counterparts. ${ }^{11}$ There are also examples of intermediate systems where the self-assembly of ligands and metal ions results in a dynamic combinatorial library where a number of oligomers are formed in solution i.e. $\left[\mathrm{M}_{x} \mathrm{~L}_{x}\right]^{n+}$ where $x=2,3,4,5$, etc. ${ }^{12}$

In this communication we describe how the formation of either dinuclear double-stranded or pentanuclear circular helicates can be controlled by inter-ligand steric interactions which, in turn, are governed by the size of the metal ion. This approach allows for the specific formation of either of the two structures and gives valuable insight into some of the factors which control the formation of cyclic helicates.

The ligand $\mathrm{L}^{1}$, which was prepared by the reaction of 2,2'-bipyridine-6-thioamide with 1,3-di( $\alpha$-bromoacetyl)benzene, contains two tridentate binding domains separated by a phenylene ring (Fig. 1). Reaction of this ligand with $\mathrm{Cd}\left(\mathrm{ClO}_{4}\right)_{2} \cdot 6 \mathrm{H}_{2} \mathrm{O}$ in $\mathrm{MeNO}_{2}$ results in a colourless solution, from which crystals are formed upon slow diffusion of dichloromethane. In the ESI mass spectrum, peaks at $m / z$ $1076\left(\left\{\left[\mathrm{Cd}_{2}\left(\mathrm{~L}^{1}\right)\right]\left(\mathrm{ClO}_{4}\right)_{3}\right\}^{+}\right)$and $1629\left(\left\{\left[\mathrm{Cd}_{2}\left(\mathrm{~L}^{1}\right)_{2}\right]\left(\mathrm{ClO}_{4}\right)_{3}\right\}^{+}\right)$, with the appropriate isotope pattern for their charged states, were present indicating the formation of the dinuclear doublestranded helicate. Formation of the complex $\left[\mathrm{Cd}_{2}\left(\mathrm{~L}^{1}\right)_{2}\right]\left(\mathrm{ClO}_{4}\right)_{4}$ was confirmed by a single crystal X-ray diffraction study (Fig. 2). $\ddagger$ In the solid-state the ligand partitions into two tridentate domains, each comprising a thiazole-pyridyl-pyridyl

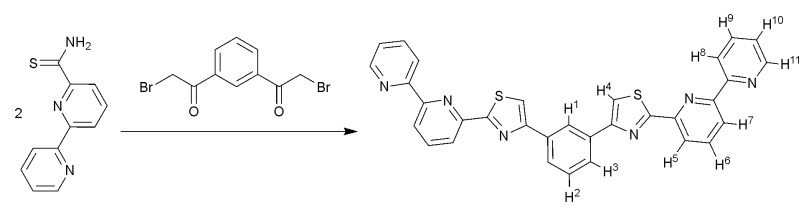

Fig. 1 Synthesis of $\mathrm{L}^{1}$.

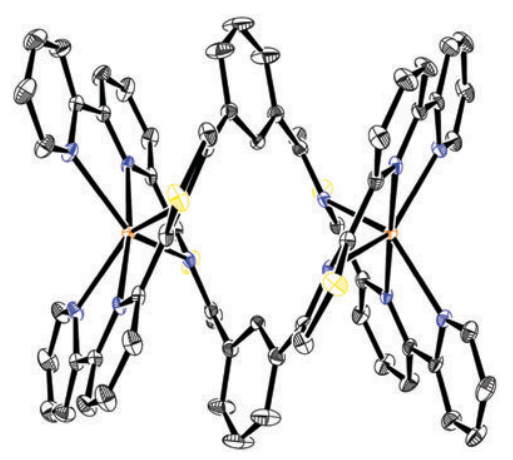

Fig. 2 Ortep plot of the complex cation $\left[\mathrm{Cd}_{2}\left(\mathrm{~L}^{1}\right)_{2}\right]^{4+}$ at $30 \%$ probability (hydrogens omitted for clarity). 


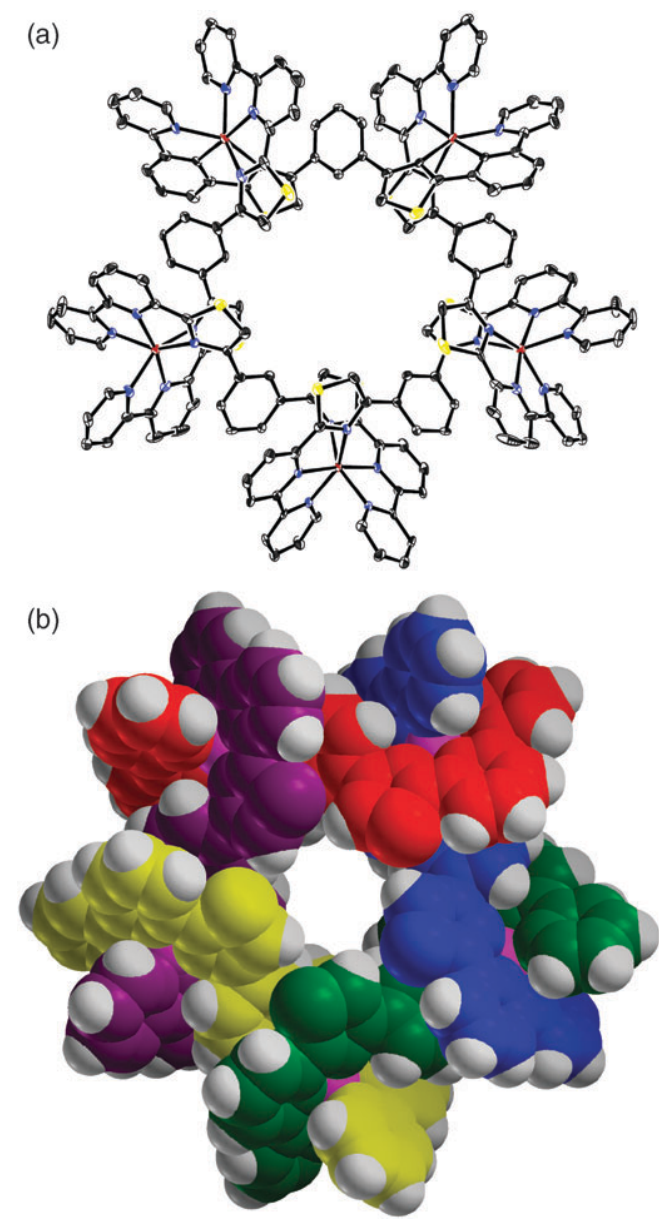

Fig. 3 Two views of the complex cation $\left[\mathrm{Zn}_{5}\left(\mathrm{~L}^{1}\right)_{5}\right]^{10+}$ : a conventional ortep view at $30 \%$ probability (top, hydrogens omitted for clarity) and a space-filling picture showing atoms with their van der Waals radii (bottom).

unit linked by the 1,3-phenylene spacer. The cadmium(II) centres have distorted octahedral geometries, imparted by coordination of one tridentate thiazole-pyridyl-pyridyl domain from each ligand (Cd-N: 2.282(4)-2.464(5) $\AA$ ).

Reaction of $\mathrm{L}^{1}$ with $\mathrm{Zn}\left(\mathrm{ClO}_{4}\right)_{2} \cdot 6 \mathrm{H}_{2} \mathrm{O}$ in $\mathrm{MeCN}$ again results in a colourless solution and upon layering with $\mathrm{Et}_{2} \mathrm{O}$ a micro-crystalline material appears. The ESI-MS shows a number of low nuclearity fragments $(m / z$ : 980, 1269 and 1532 corresponding to $\left\{\left[\mathrm{Zn}_{2}\left(\mathrm{~L}^{1}\right)\right]\left(\mathrm{ClO}_{4}\right)_{3}\right\}^{+},\left\{\left[\mathrm{Zn}\left(\mathrm{L}^{1}\right)_{2}\right]\left(\mathrm{ClO}_{4}\right)\right\}^{+}$and $\left\{\left[\mathrm{Zn}_{2}\left(\mathrm{~L}^{1}\right)_{2}\right]\left(\mathrm{ClO}_{4}\right)_{3}\right\}^{+}$, respectively), but also a peak at $\mathrm{m} / \mathrm{z} 1942$ corresponding to the pentanuclear species $\left\{\left[\mathrm{Zn}_{5}\left(\mathrm{~L}^{1}\right)_{5}\right]\left(\mathrm{ClO}_{4}\right)_{8}\right\}^{2+}$. Crystals suitable for X-ray diffraction were grown by layering a solution of $\mathrm{Zn}\left(\mathrm{CF}_{3} \mathrm{SO}_{3}\right)_{2}$ with $\mathrm{L}^{1}$ in $\mathrm{MeCN}$ with $\mathrm{Et}_{2} \mathrm{O}$, and structural analysis confirmed the formation of the pentanuclear cyclic helicate $\left[\mathrm{Zn}_{5}\left(\mathrm{~L}^{1}\right)_{5}\right]\left(\mathrm{CF}_{3} \mathrm{SO}_{3}\right)_{10}$ (Fig. 3a and b). In the crystal, all five $\mathrm{Zn}^{2+}$ ions are six-coordinate, arising from the coordination of two tridentate thiazole-pyridyl-pyridyl domains from two different ligands ( $\mathrm{Zn}-\mathrm{N}: 2.072(8)-2.327(8) \AA$ ). The 1,3-phenylene spacers bridge each of the tridentate domains in an 'over-andunder' conformation, giving rise to a helical cyclic oligomer as opposed to a face-to-face array associated with more grid-like architectures.§

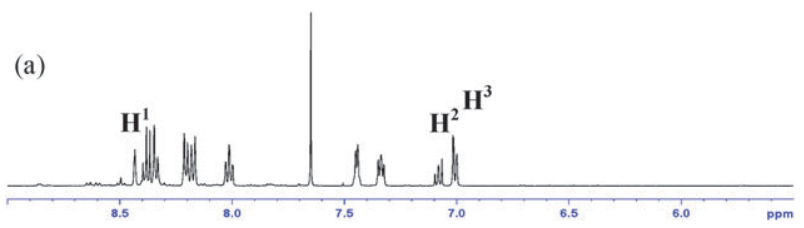

(b)

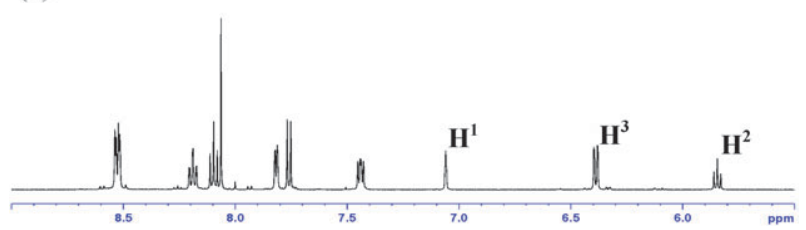

Fig. 4 Aromatic regions in the ${ }^{1} \mathrm{H}$ NMR spectra $\left(\mathrm{CD}_{3} \mathrm{NO}_{2}\right)$ of (a) $\left[\mathrm{Cd}_{2}\left(\mathrm{~L}^{1}\right)_{2}\right]^{4+}$ and (b) $\left[\mathrm{Zn}_{5}\left(\mathrm{~L}^{1}\right)_{5}\right]^{10+}$.

Reaction of $\mathrm{L}^{1}$ with $\mathrm{Cd}^{2+}$ or $\mathrm{Zn}^{2+}$ ions not only gives very different structures in the solid-state, ${ }^{1} \mathrm{H}$ NMR $\left(\mathrm{CD}_{3} \mathrm{NO}_{2}\right)$ studies also suggest that the respective structures are retained in solution. The one-dimensional ${ }^{1} \mathrm{H}$ NMR spectra of solutions containing $\left[\mathrm{Cd}_{2}\left(\mathrm{~L}^{1}\right)_{2}\right]\left(\mathrm{ClO}_{4}\right)_{4}$ and $\left[\mathrm{Zn}_{5}\left(\mathrm{~L}^{1}\right)_{5}\right](\mathrm{OTf})_{10}$ in $\mathrm{CD}_{3} \mathrm{NO}_{2}$ show the expected 11 aromatic resonances for complexes of $D_{2}$ and $D_{5}$ symmetry respectively (Fig. 4). For both species, protons on the tridentate chelate units appear between 7.0 and $8.4 \mathrm{ppm}$, consistent with the aromatic heterocycles on $\mathrm{L}^{1}$ being coordinated to one of the two metal ions. For the pentanuclear species, however, the three protons on the bridging phenylene unit resonate at much lower frequency (6.5-5.9 ppm) than those in $\left[\mathrm{Cd}_{2}\left(\mathrm{~L}^{1}\right)_{2}\right]^{4+}$. In both structures this central phenylene ring is sandwiched between the internal pyridyl rings of the two thiazole-pyridine-pyridine tridentate domains, but in the pentanuclear helicate this packing motif is more compact, with an average centroid ...centroid distance of 3.9(1) $\AA$ ( $c f .4 .2(1) \AA$ for the dinuclear helicate). The phenylene protons in $\left[\mathrm{Zn}_{5}\left(\mathrm{~L}^{1}\right)_{5}\right]^{10+}$ are thus more exposed to the shielding ring currents produced by the aromatic heterocycles on the two overlapping ligand strands, and hence the unusually low field chemical shifts. Additionally, ${ }^{1} \mathrm{H}-{ }^{1} \mathrm{H}$ NOESY spectra evidence a complex network of inter-ligand through-space interactions for $\left[\mathrm{Zn}_{5}\left(\mathrm{~L}^{1}\right)_{5}\right]^{10+}$, where the cyclic arrangement brings up to seven pairs of protons into sufficiently close proximity for dipole-dipole induced relaxation effects to be observed (see ESI $\dagger$ ). None of these interactions occur for $\left[\mathrm{Cd}_{2}\left(\mathrm{~L}^{1}\right)_{2}\right]^{4+}$, however, in which the shortest corresponding non-bonded distances are up to $c a .2 \AA$ longer in the solidstate structure. For $\left[\mathrm{Zn}_{5}\left(\mathrm{~L}^{1}\right)_{5}\right]^{10+}$, a diagnostic intra-ligand NOE effect also occurs between phenylene proton $\mathrm{H}^{1}$ and thiazole proton $\mathrm{H}^{4}$, whose non-bonded distance is $c a .2 .5 \AA$ in the solid-state structure ( $c f . c a .4 .3 \AA$ in $\left[\mathrm{Cd}_{2}\left(\mathrm{~L}^{1}\right)_{2}\right]^{4+}$ ).

Further evidence for the retention of the respective solidstate structures in solution was obtained by diffusion ordered NMR spectroscopy. Translational self-diffusion coefficients (in $\mathrm{CD}_{3} \mathrm{NO}_{2}, 298 \mathrm{~K}$ ) were determined to be $3.4(3) \times 10^{-10}$ and $6.3(2) \times 10^{-10} \mathrm{~m}^{2} \mathrm{~s}^{-1}$ for $\left[\mathrm{Zn}_{5}\left(\mathrm{~L}^{1}\right)_{5}\right]^{10+}$ and $\left[\mathrm{Cd}_{2}\left(\mathrm{~L}^{1}\right)_{2}\right]^{4+}$ respectively. Conversion of these values into meaningful hydrodynamic radii is not trivial since microfrictional and shape effects can profoundly influence the apparent relationship between diffusion constant and molecular size..$^{13}$ The significantly lower value obtained for $\left[\mathrm{Zn}_{5}\left(\mathrm{~L}^{1}\right)_{5}\right]^{10+}$ is nonetheless consistent with it being the larger of the two diffusing species in solution. 
It is worth noting that the dicadmium(II) helicate was obtained as the perchlorate salt whereas single crystals of the pentanuclear structure were only successfully obtained in the presence of the triflate anion. Indeed, in the latter structure, a disordered triflate anion resides within the central cavity of the circular complex cation. To investigate the potential role of counter anion in the two self-assembly reactions, therefore, solutions $\left(\mathrm{CD}_{3} \mathrm{NO}_{2}\right)$ containing the two respective assemblies were monitored by ${ }^{1} \mathrm{H} \mathrm{NMR}$ as increasing amounts of the other's anion were added (as the tetrabutylammonium salts). Even in the presence of 20 eq. of the corresponding anion, however, no changes were observed in either case and so the latter's influence in directing the assembly is clearly minimal.

An alternative explanation for why $\mathrm{L}^{1}$ gives such markedly different structures with the two spherical $\mathrm{d}^{10}$ cations therefore requires consideration of the potential steric interactions occurring between the protons on the central phenylene units in the two respective structures. Although these units function well in partitioning the ligands into two tridentate domainsthus preventing the undesired mononuclear species - the formation of the dinuclear helicate structure brings them into relatively close proximity with one another (see Fig. 2). Indeed, the inter-strand $\mathrm{C}^{1} \cdots \mathrm{C}^{1 \prime}$ distance between these two rings is $c a$. $4.2 \AA$ in $\left[\mathrm{Cd}_{2}\left(\mathrm{~L}^{1}\right)_{2}\right]^{4+}$, and examination of the van der Waals radii reveals marginal surplus space between these inward facing $\mathrm{H}^{1}$ protons. Six coordinate zinc(II) is, needless to say, smaller than cadmium(II) (0.75 vs. $0.95 \AA$ respectively). Due to correspondingly shorter $\mathrm{Zn}-\mathrm{N}$ bonds, therefore, it is likely that any steric and/or electrostatic repulsion between these protons would be significantly emphasized in an isostructural dizinc(II) helicate. The latter presumably being destabilized in this manner results in the formation of an alternative species which does not require that the two phenylene rings reside in such close proximity. In this case, the alternative is the observed pentanuclear cyclic helicate, whose apparent high relative stability ensures its quantitative formation and retention in the gas-, solution- and solid-states.

These results demonstrate how subtle changes in the metal/ ligand bond distances can influence inter-ligand steric interactions and have a pronounced effect on the outcome of a self-assembly reaction.

\section{Notes and references}

$\ddagger$ Crystal data for $\left[\mathrm{Cd}_{2}\left(\mathrm{C}_{32} \mathrm{H}_{20} \mathrm{~N}_{6} \mathrm{~S}_{2}\right)_{2}\right]\left[\mathrm{ClO}_{4}\right]_{4} \cdot 2 \mathrm{CH}_{2} \mathrm{Cl}_{2}: M=1897.77$, monoclinic $C 2 / c, a=24.3339(8), b=12.1082(4), c=28.2739(12) \mathrm{A}$, $\beta=112.7890(10)^{\circ}, V=7680.3(5) \AA^{3}, Z=4 ; \rho_{\text {calc }}=1.641 \mathrm{Mg} \mathrm{m}^{-3}$, $F(000)=3792$; crystal dimensions $0.10 \times 0.09 \times 0.08 \mathrm{~mm}^{-3} ; \mu\left(\mathrm{Mo}_{\mathrm{K} \alpha}\right)$ $=0.71073 \mathrm{~mm}^{-1}, T=100 \mathrm{~K}$. A total of 27701 reflections were measured in the range $1.82^{\circ} \leq \theta \leq 25.68^{\circ}$ ( $h k l$ range indices: $-29 \leq$ $h \leq 29,-14 \leq k \leq 9,-34 \leq l \leq 34), 7282$ unique reflections $\left(R_{\text {int }}=0.0318\right)$. The structures were refined on $F^{2}$ to $R_{\mathrm{w}}=0.1606$, $R=0.0586(6029$ reflections with $I>2 \sigma(I))$ and GOF $=1.038$ on $F^{2}$ for 461 refined parameters, 0 restraints. Largest peak and hole 3.682 and $-1.318 \mathrm{e}^{-3}$. CCDC 748335 .

- $\left[\mathrm{L}^{1}\right]_{\mathrm{tot}}=3 \mathrm{mM}$; solutions prepared in situ and left to equilibrate for $24 \mathrm{~h}$ at room temperature.

$\S$ Crystal data for $\left[\mathrm{Zn}_{5}\left(\mathrm{C}_{32} \mathrm{H}_{20} \mathrm{~N}_{6} \mathrm{~S}_{2}\right)_{5}\right][\mathrm{OTf}]_{10} \cdot 7 \mathrm{MeCN}: M=4868.23$, monoclinic $C 2 / c, a=22.5172(19), b=24.756(2), c=36.000(3) \AA$, $\beta=96.827(2)^{\circ}, V=19926(3) \AA^{3}, Z=4 ; \rho_{\text {calc }}=1.623 \mathrm{Mg} \mathrm{m}^{-3}$, $F(000)=9856$; crystal dimensions $0.09 \times 0.07 \times 0.07 \mathrm{~mm}^{-3} ; \mu\left(\mathrm{Mo}_{\mathrm{K} \alpha}\right)=$ $0.911 \mathrm{~mm}^{-1}, T=100 \mathrm{~K}$. A total of 72997 reflections were measured in the range $1.74^{\circ} \leq \theta \leq 25.69^{\circ}$ ( $h \mathrm{kl}$ range indices: $-27 \leq h \leq 27$, $-29 \leq k \leq 30,-43 \leq l \leq 43), 18926$ unique reflections $\left(R_{\text {int }}=\right.$ 0.0416 ). The structures were refined on $F^{2}$ to $R_{\mathrm{w}}=0.3224, R=0.1236$ (14889 reflections with $I>2 \sigma(I))$ and GOF $=1.149$ on $F^{2}$ for 1270 refined parameters, 411 restraints. Largest peak and hole 1.862 and $-1.891 \mathrm{e}^{-3}$. CCDC 748336. Scattering contributions from diffuse solvent were removed using the Squeeze routing in Platon. ${ }^{14}$ Crystals of both complexes grew as stacked platelets and the diffraction data were always to some extent contaminated with reflections from crystal sub-domains. The present data sets were the best of numerous trials, but the consequences of reflection overlap, in particular at low angle, can still be seen in the relatively high residuals, unusual weighting coefficients and the presence of some large (up to $3.6 \mathrm{e}^{-3}$ ) residual electron density peaks in chemically unfeasible positions. Despite these problems, the quality of the data is largely sufficient to unambiguously determine atomic connectivity in the complex cations.

1 J.-M. Lehn, Supramolecular Chemistry, VCH, Weinheim, 1995; J. W. Steed and J. L. Atwood, Supramolecular Chemistry, John Wiley and Sons, Chichester, 2000.

2 M. J. Hannon and L. J. Childs, Supramol. Chem., 2004, 16, 7.

3 M. Albrecht, Chem. Rev., 2001, 101, 3547; M. Albrecht, Chem. Soc. Rev., 1998, 27, 281; M. Albrecht, Supramolecular templating in the formation of helicates, in Topics in Current Chemistry, ed. C. A. Schalley, F. Vögtle and K.-H. Dötz, Springer, Berlin, 2004, vol. 248, p. 105.

4 C. Piguet, G. Bernardinelli and G. Hopfgartner, Chem. Rev., 1997, 97, 2005 .

5 E. C. Constable, Comprehensive Supramolecular Chemistry, in Polynuclear Transition Metal Helicates, ed. J.-P. Sauvage, Elsevier, Oxford, vol. 9, 1996, p. 213.

6 For recent examples of metallo-helicates see: S. P. Argent, H. Adams, L. P. Harding, T. Riis-Johannessen, J. C. Jeffery and M. D. Ward, New J. Chem., 2005, 29, 904; Q. Z. Sun, Y. Bai, G. J. He, C. Y. Duan, Z. H. Lin and Q. J. Meng, Chem. Commun., 2006, 2777; M. Cantuel, F. Gumy, J. C. G. Bunzli and C. Piguet, Dalton Trans., 2006, 2647; M. Hutin, R. Frantz and J. R. Nitschke, Chem.-Eur. J., 2006, 12, 4077.

7 C. R. Rice, S. Wörl, J. C. Jeffery, R. L. Paul and M. D. Ward, Chem. Commun., 2000, 1529; C. R. Rice, S. Wörl, J. C. Jeffery, R. L. Paul and M. D. Ward, J. Chem. Soc., Dalton Trans., 2001, 550; C. R. Rice, C. J. Baylies, J. C. Jeffery, R. L. Paul and M. D. Ward, Inorg. Chim. Acta, 2001, 324, 331.

8 B. Hasenknopf, J.-M. Lehn, N. Boumediene, E. Leize and A. Van Dorsselaer, Angew. Chem., Int. Ed., 1998, 37, 3265; B. Hasenknopf, J.-M. Lehn, N. Boumediene, A. Dupont-Gervais, A. Van Dorsselaer, B. Kneisel and D. Fenske, J. Am. Chem. Soc., 1997, 119, 10956.

9 S. P. Argent, H. Adams, T. Riis-Johannessen, J. C. Jeffery, L. P. Harding, O. Mamula and M. D. Ward, Inorg. Chem., 2006, 45, 3905 .

10 J. Hamblin, F. Tuna, S. Bunce, L. J. Childs, A. Jackson, W. Errington, N. W. Alcock, H. Nierengarten, A. V. Dorsselaer, E. Leize-Wagner and M. J. Hannon, Chem.-Eur. J., 2007, 13, 9286; Y. Pang, S. Cui, B. Li, J. Zhang, Y. Wang and H. Zhang, Inorg. Chem., 2008, 47, 10317.

11 L. J. Childs, M. Pascu, A. J. Clarke, N. W. Alcock and M. J. Hannon, Chem.-Eur. J., 2004, 10, 4291; L. J. Childs, N. W. Alcock and M. J. Hannon, Angew. Chem., Int. Ed., 2002, 41, 4244.

12 G. Baum, E. C. Constable, D. Fenske, C. E. Housecroft and T. Kulke, Chem. Commun., 1999, 195.

13 A. Macchioni, G. Ciancaleoni, C. Zuccaccia and D. Zuccaccia, Chem. Soc. Rev., 2008, 37, 479.

14 A. L. Spek, Acta Crystallogr., Sect. A, 1990, 46, C-34; A. L. Spek, PLATON-A Multipurpose Crystallographic Tool, Utrecht University, Utrecht, The Netherlands, 2003. 